\title{
Development of an Ecological Dynamic Model for a Duckweed-Donated Urban Eutrophic Wetland
}

\author{
Z. M. Li, Y. X. Liu, B. Q. Dong, and Y. W. Zhao
}

\begin{abstract}
An ecological dynamic model based on phosphorus cycling of ecosystem was developed for Hanshiqaio wetland in North China. The state variables include dissolved inorganic phosphorus (P), duckweed (FP), submerged plant (SP), phytoplankton (A), zooplankton (Z), detritus (D) and dissolved inorganic phosphorus in pore water (PPP). In this study, a sub-model of duckweed was developed and integrated with other sub-models of submerged plants and phytoplankton into one comprehensive model. This model was calibrated and validated based on the data of three types of water areas with different ecological conditions. The simulation value and observation value agree well. This model is then used to evaluate the effects of ecological restoration methods. Three ecological restoration methods were set to predict the trend of $P$ concentrations following the change of controlling methods for duckweed. We should harvest all duckweed before August and introduce duckweed into wetland after August to achieve better effect of ecological restoration. The model provides theoretical guidance and technical support for wetland ecological restoration.
\end{abstract}

Index Terms-Duckweed, ecological dynamic model, phosphorus cycling, urban wetland.

\section{INTRODUCTION}

Urban wetland is a special ecosystem in city, which have important functions on ecological environment and social service. It provides many valuable ecological benefits such as water purification, flood control, and local microclimate adjustment, as well as scenery creation and cultural heritage. In the past few decades, urban wetlands are strongly influenced by long term discharge of untreated domestic and industrial wastewaters, storm water runoff, accidental spills and direct solid waste dumping as a result of rapid urbanization accompanied by weak urban planning [1] Eutrophication becomes the major threat of urban wetland ecosystem.

The Hanshiqiao wetland was located in Shunyi district, city of Beijing with an area of about $19 \mathrm{~km}^{2}$ (Fig. 1). It was a typical plant-dominated shallow freshwater marsh wetland in North China. Influenced by urban and agricultural development and other activities, the ecological functions of Hanshiqiao wetland were seriously damaged. In 2005 the Hanshiqiao wetland nature reserve was established and the ecological remediation had great impact on delaying the

Manuscript received May 25, 2015; revised September 18, 2015. This work was supported in part by the Scientific and Technological Supporting Program of China (2012BAC13B02) and the Natural Science Foundation of China (No. 51279009).

The authors are with State Key Laboratory of Water Environment Simulation, School of Environment, Beijing Normal University, China (e-mail: tjlzm@mail.bnu.edu.cn, yanxialiu1006@163.com, lindadbq@163.com, awei1974@bnu.edu.cn). wetland degradation [2], [3]. However, at present, the Hanshiqiao wetland has no supply of upstream water and the recycled water supply is limited. Combined with agricultural and tourist activities, the Hanshiqiao wetland is at high eutrophication level and the pollution of core area is obviously more serious than the tourist area [4]. High eutrophication level leads to the boom of the duckweed. It covers nearly $80 \%$ to $90 \%$ of the water area in summer and in the early autumn. It may harm to the ecological condition of the wetland [5], [6].

Ecological models are of great importance to simulate the effects of macrophytes on the aquatic ecosystem. The wetland models considered ecological impact of macrophytes has experienced from simple to complex. A shallow lake ecological model based upon phytoplankton population dynamics was developed by Jørgensen and applied to Lake Glums $\varnothing$ [7]. Xu et al. developed a model for Lake Chaohu by combining the phosphorus cycles, plankton, macrophytes and fish biomass dynamics and discussed the effect of increasing the macrophyte area as the restoration method [8], [9]. Xu developed a STELLA model for the structure of nutrient and phosphorus cycling within the food web, and evaluated and predicted the health status of Baiyangdian wetland. This model added submerged plants as a sub-model and simulated the ecological effects of submerged plant [10]. Zhao sought to establish a zoning-based ecological model for Baiyangdian wetland, and to assess the effects of different ecological restoration schemes by modeling the phosphorus cycle [11].

However, duckweed as the typical floating plant in tropical and subtropical shallow wetland, was not considered in ecological dynamic models. This lead to the low model accuracy and applicability. Some studies were focus on the ecological effects of duckweed on the eutrophic wetland and developed some mechanism models about the growth mechanism of the duckweed and the absorption to nutrients. Samir Lasfar developed a comprehensive model based on the intrinsic growth rate to simulate the duckweed growth under controlled eutrophication conditions. This model permits to differentiate the effect of duckweed mat density from that of temperature, photoperiod. It can be used to simulate the change of growth rate under controlled conditions [12], [13]. Kun Zhang developed mathematical models to describe nitrogen uptake and duckweed growth experimentally to study the kinetics of ammonium uptake under various concentrations [14]. But these models only explain the growth mechanism of duckweed and the absorption to nutrients in experiment lab. These can not reflect the field conditions of the wetland. Thus, it is necessary to develop a sub-model of duckweed and integrate sub-models of duckweed, submerged plants and phytoplankton into one comprehensive model.

The objective of this study is to develop a model that 
describes the effects of duckweed booming in phosphorus cycle for urban eutrophic wetland. This model is then used to evaluate the effects of ecological restoration methods and provides theoretical guidance and technical support for wetland ecological restoration.

\section{MATERIALS AND METHODS}

\section{A. Data Sources}

The data for assessment indicator calculation were acquired from three sampling sites (see Table I) from October 2013 to October 2014. Physical and chemical indices, including secchi disk depth (SD), chlorophyll-a (chla), dissolved inorganic phosphorus (P) and biological indices containing biomass of zooplankton, benthonic animals, macrophytes (duckweed and submerged plants) and detritus, were measured according to Jin et al. [15].

TABLE I: SUMMARY OF BASIC SITUATION FOR SAMPLING SITES

\begin{tabular}{ccc}
\hline \hline Sampling site & Location & Characteristic \\
\hline$\# 1$ & Near the water outlet & Duckweed booming in summer and autumn, water does not flow out of this area in spring \\
$\# 2$ & Middle of core area & No duckweed \\
$\# 3$ & Near the inlet of reclaimed water & Duckweed booming in summer and autumn \\
\hline \hline
\end{tabular}

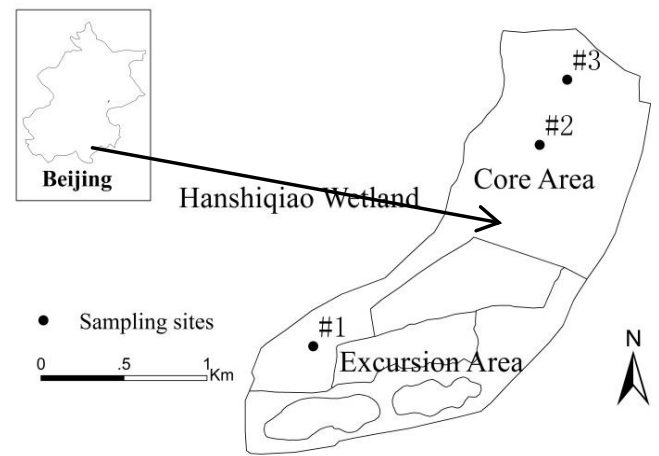

Fig. 1. Study area.

\section{B. Model Structure}

A ecological dynamic model is established based on the data acquired from field monitoring during Apr 2014-Oct 2014 for Hanshiqiao Wetland using the software Stella 9.0. Eutrophication is the main problem concerning wetland ecosystem. So the model structure is designed on the basis of the phosphorus cycling within the food wed. According to the monitoring result of water quality, it is assumed that phosphorus is the limiting factor.

The state variables include dissolved inorganic phosphorus (P), duckweed (FP), submerged plant (SP), phytoplankton (A), zooplankton (Z), detritus (D) and dissolved inorganic phosphorus in pore water (PPP). The initial values of the 8 state variables are directly or calculated from the observations in April, 2014.

The forcing functions to the wetland ecosystem mainly included solar radiation (SR), water temperature $(\mathrm{T})$, water depth (depth), phosphorus loadings and removal of floating plant and submerged plant.

The most important processes considered in the model were as follows (The conceptual diagram of the ecological dynamic model is shown in Fig. 2; Definition of each state variable and processes included in the model are shown in Table II and III):

1) Growth of the duckweed was a function of time, upper limit of the mat density and the intrinsic growth rate of duckweed. The Michaelis-Menten kinetics model can be used to described the intrinsic growth rate of duckweed $\left(r_{i}\right) \cdot r_{i}$ was a function of temperature, photoperiod and concentrations of nutrients (see in Table III). The model was calibrated using data from laboratory experiments and validated using experimental data from the literature by Samir Lasfar [12]. Floating plant was assumed to only take up nutrients from the water. Absorption of phosphorus is considered all into duckweed biomass. In the literature, the phosphorus content of duckweed dry weight was from 0.004 to $0.006 \mathrm{mgP} \mathrm{mg}^{-1} \mathrm{DW}$ [16]. In this model, the value of constant is 0.0041 . For this study, it is considered that the shading effects are related to the biomass of duckweed. Thus, the shading effects can be expressed with a parameter 's'.

$$
S=1-\frac{F P}{130.61}
$$

where $s$ is light transmittance. $\mathrm{FP}\left(\mathrm{g} / \mathrm{m}^{2}\right)$ is the biomass of duckweed. When the water surface is all covered by duckweed and almost no light can transmit through the duckweed, the biomass is $130.61 \mathrm{~g} / \mathrm{m}^{2}$. This value was monitored to the spot.

2) Growth of phytoplankton and submerged plant was a function of time, water temperature, light, phosphorus concentration. Michaelis-Menten equation was used to describe the nutrient limitation. The light extinction through the water depth was considered to be due to shading effects of phytoplankton and submerged plants. Phytoplankton was assumed to only take up nutrients from water while submerged plants acquired nutrients from both water and pore water. The uptake rate for phosphorus was assumed as 0.01 , respectively. If the nutrient concentration of water is high, it was presumed that the growth was reduced in half when the concentration of dissolved inorganic phosphorus in water exceeded $1 \mathrm{mg} / \mathrm{L}$, respectively. Grazing of zooplankton on phytoplankton was a function of time, temperature, concentration of phytoplankton. It was assumed that the grazing efficiency was $60 \%$.

3) Mortality of phytoplankton, zooplankton and submerged plants was an exponential function of temperature and expressed as a firs order reaction. The dead submerged plants were considered to directly settle to sediment phosphorus at a ratio of 7:1. Mortality of duckweed was $0.05 \mathrm{~d}^{-1}$.

4) Settling of phytoplankton and detritus was a function of temperature and expressed as a first order reaction. The radio of phosphorus in settled phytoplankton and detritus was assumed as 0.01 .

5) Mineralization of detritus, sediment phosphorus was a first order reaction, which was depended on the temperature and expressed as an exponential function of 
temperature 。

6) Diffusion of phosphorus took place between pore water and water due to the differences in phosphorus concentrations. It was assumed that diffusion only happened when the concentrations of phosphorus in pore water were relatively higher than those in water and an IF function was used to describe this process.

7) Duckweed was considered to be eaten by fish and wild duck. In summer and autumn, duckweed was reaping by staff.

TABLE II: DEFINITION OF EACH STATE VARIABLE

\begin{tabular}{|c|c|c|}
\hline Variables & Definition & Unit \\
\hline Up by $A$ & Uptaking phosphorus rate by phytoplankton & $\mathrm{mg} / \mathrm{L}$ per day \\
\hline Up by FP & Uptaking phosphorus rate from water by duckweed & $\mathrm{mg} / \mathrm{L}$ per day \\
\hline Up by SP & Uptaking phosphorus rate from water by submerged plant & $\mathrm{mg} / \mathrm{L}$ per day \\
\hline Up PP & Uptaking phosphorus rate from pore water by submerged plant & $\mathrm{mg} / \mathrm{L}$ per day \\
\hline Grazing & Grazing phytoplankton by zooplankton & $\mathrm{mg} / \mathrm{L}$ per day \\
\hline Inflow $\mathrm{P} 0$ & Inflow dissolved inorganic phosphorus rate to the wetland & $\mathrm{mg} / \mathrm{L}$ per day \\
\hline Mor 1 & Mortality of phytoplankton & $\mathrm{mg} / \mathrm{L}$ per day \\
\hline Mor 2 & Mortality of zooplankton & $\mathrm{mg} / \mathrm{L}$ per day \\
\hline Mor 3 & Mortality of submerged plant & $\mathrm{g} / \mathrm{m}^{2}$ per day \\
\hline Mor 5 & Mortality of duckweed & $\mathrm{g} / \mathrm{m}^{2}$ per day \\
\hline Harvest & Reaping of submerged plant & $\mathrm{g} / \mathrm{m}^{2}$ per day \\
\hline Harvest 2 & Reaping of duckweed & $\mathrm{g} / \mathrm{m}^{2}$ per day \\
\hline Sett 1 & Settling phytoplankton to exchangeable phosphorus in sediment & $\mathrm{mg} / \mathrm{L}$ per day \\
\hline Sett 3 & Settling detritus to exchangeable phosphorus in sediment & $\mathrm{mg} / \mathrm{L}$ per day \\
\hline Min 1 & Mineralized phosphorus rate from detritus & $\mathrm{mg} / \mathrm{L}$ per day \\
\hline $\operatorname{Min} 2$ & Settling detritus to exchangeable phosphorus in sediment & $\mathrm{mg} / \mathrm{L}$ per day \\
\hline Dif $P$ & Diffusion phosphorus to water phase from pore water & $\mathrm{mg} / \mathrm{L}$ per day \\
\hline
\end{tabular}

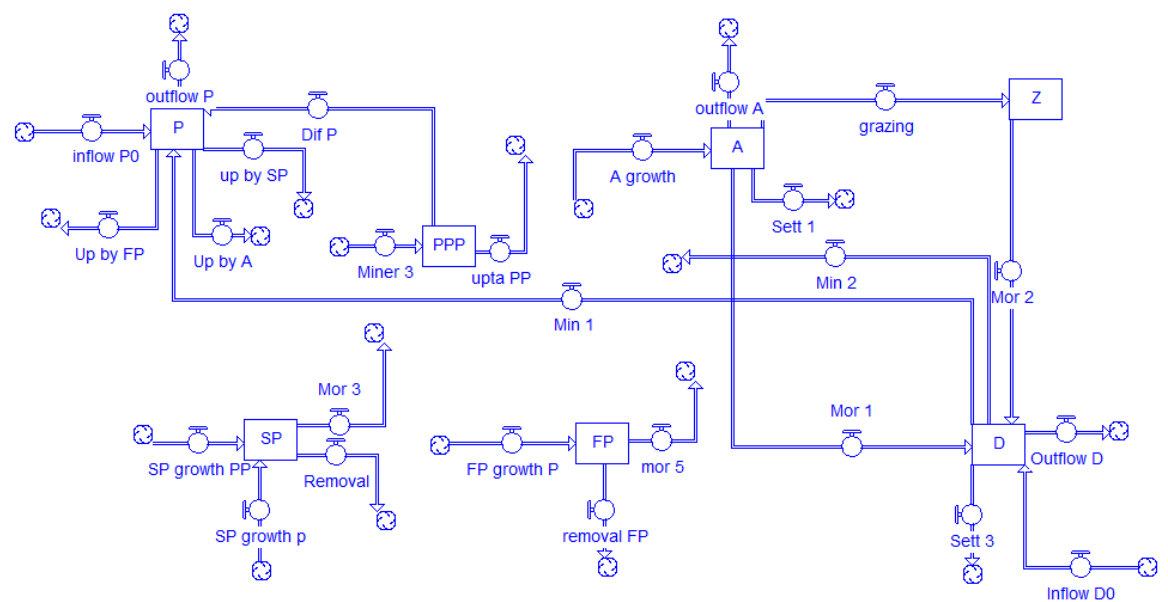

Fig. 2. The conceptual diagram of the ecological dynamic model for Hanshiqiao wetland.

\section{Potential Ecological Restoration Methods}

Based on recognition on the driving factors of Hanshiqiao wetland degradation, our study mainly sets management measures from the aspects of changing aquatic organisms, especially for controlling the duckweed booming. Management of duckweed booming is the key to water ecological restoration of Hanshiqiao wetland. And it is also the focus of our study. Accordingly, we set three scenarios for controlling duckweed booming and evaluation analysis:

Scenario 1: Keep the reclaimed water supply quality and harvest no duckweed;

Scenario 2: Keep the reclaimed water supply quality and harvest $60 \%$ of duckweed every month;

Scenario 3: Keep the reclaimed water supply capacity and harvest all duckweed to ensure that no duckweed on the surface of water.

\section{RESUlTS AND DisCUSSION}

\section{A. The Model Calibration and Validation}

The sensitivity analysis mainly analyzed 21 parameters on the 7 state variables (dissolved inorganic phosphorus in water, detritus, dissolved inorganic phosphorus in pore water, phytoplankton biomass, zooplankton biomass, floating plant biomass and submerged plant biomass). The sensitivity level of parameter i was according to sensitivity class setted by Lenhart et al. [17]. Results (Table IV) show that some parameters, such as KA, KP and MSP were more effective for determining most of the key status variables. However, for some status variables, other impact parameters were more important. For instance, $\mathrm{P}$ was more sensitive to KA, KP and KPP.

The calibration of each parameter was performed by 
Nash-Sutcliffe efficiency coefficient $\left(\mathrm{E}_{\mathrm{NS}}\right)$ until the values of $\mathrm{E}_{\mathrm{NS}}$ were above 0.7 [18]. Sampling site \#3 was selected for model calibration based on the measured data from April 2014 to October 2014. The comparison of simulations and observations for important state variables including dissolved inorganic phosphorus $(\mathrm{P})$ are presented in Fig. 3. The value of $\mathrm{E}_{\mathrm{NS}}$ is 0.98 . The figure shows that the concentration of $\mathrm{P}$ fell from April to October. This result may be due to absorption of duckweed growth to nutrients.

TABLE III: PROCESSES INCLUDED IN THE MODEL

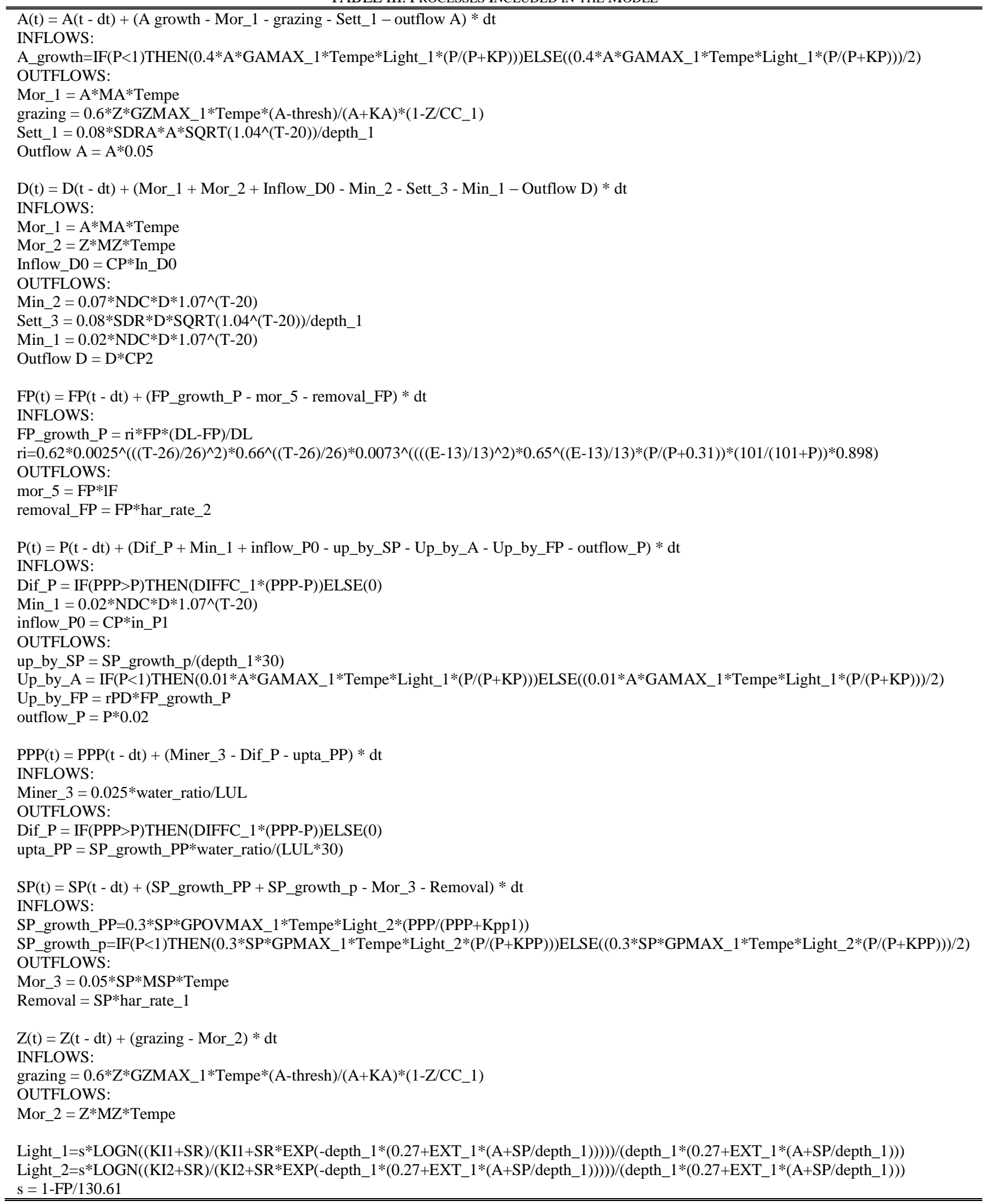

The validation results of the key status variables of dissolved inorganic phosphorus for sampling sites \#1 and \#2 are shown in Fig. 4 and Fig. 5. The value of $E_{N S}$ is 0.85 and 0.91 . Fig. 4 shows the change of $P$ at sampling site \#1, which is outlet of the Hanshiqiao wetland. In April and May, water does not flow out of this area. This leads to enrichment of nutrients in this area. In the later month, water flows out of this area due to drainage of small dam and absorption of duckweed. The concentration of $\mathrm{P}$ rises in the spring and falls in summer and autumn. From simulation results of area with 
no duckweed (Fig. 5), we can find that the concentration of $\mathrm{P}$ rises before July and then falls. This may be caused by dominance shift between phytoplankton and submerged plants. The dominance shift can influence the phosphorus cycle in the wetland.

TABLE IV: The CoRresponding Sensitive PaRAmeters of EACH State VARIABLES

\begin{tabular}{ccc}
\hline \hline State variables & High sensitive parameters & $\begin{array}{c}\text { Very high sensitive } \\
\text { parameters }\end{array}$ \\
\hline A & KA, KP, KPP, MZ & EXT, GPMAX, \\
& GPOVMAX, MSP, \\
water ratio, GAMAX \\
EXT, GPMAX, \\
P & KA, KP, KPP & waVMAX, MSP, \\
& water ratio, GAMAX \\
PPP & GPMAX, MSP & EXT, GPOVMAX, \\
& water ratio \\
$Z$ & KP, MSP, water ratio & EXT, GPMAX, \\
& GPOVMAX \\
D & KP, GAMAX, MZ & EXT, GPMAX, \\
& GPOVMX, MSP, \\
FP & EXT & water ratio \\
SP & EXT & - \\
\hline \hline
\end{tabular}

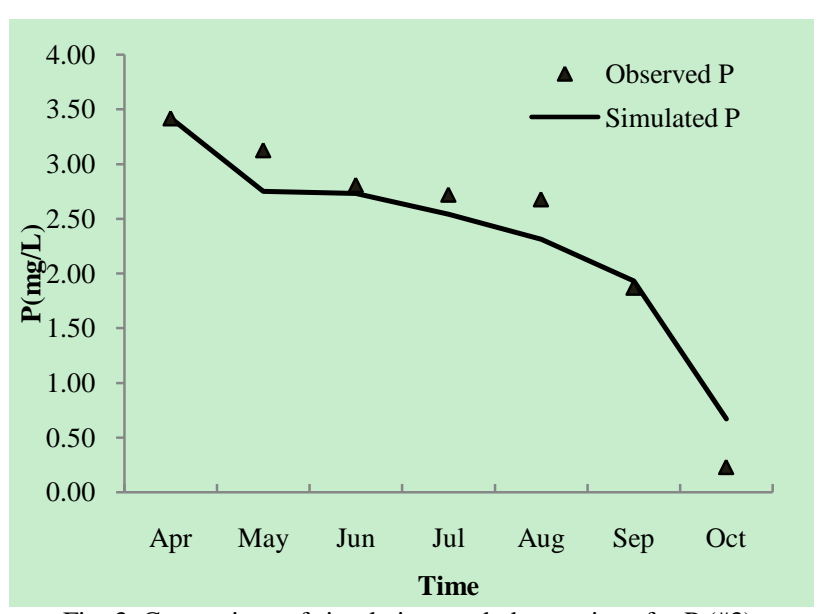

Fig. 3. Comparison of simulations and observations for $\mathrm{P}(\# 3)$.

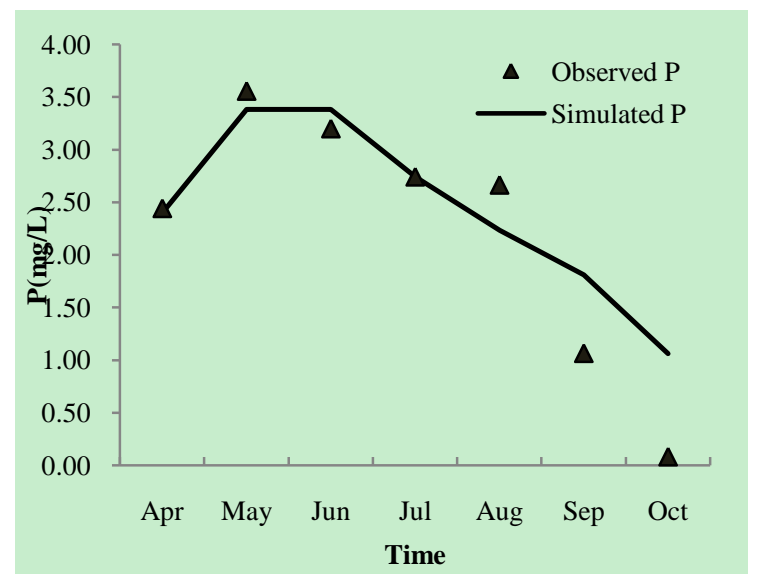

Fig. 4. Comparison of simulations and observations for $\mathrm{P}(\# 1)$.

\section{B. Effect Analysis of Ecological Restoration Methods}

In the process of wetland restoration and management, managers usually want to determine which restoration method is effective in reducing the phosphorus concentration and optimize the restoration methods. In this study, we choose sampling site $3 \#$ as the scenario simulation area. The application of ecological dynamic model can predict the trend of $\mathrm{P}$ concentrations following the change of controlling methods for duckweed. Comparing the prediction results of three scenarios, we can find that Scenario 3 with no duckweed is more effective in ecological restoration than Scenarios 1 and 2 before August. After August, Scenario 1 (no harvest) and 2 (harvest $60 \%$ every month) are more effective and have similar effects in reducing $\mathrm{P}$ concentration. These changes may be due to the shading effects of duckweed to submerged plants and phytoplankton. Before August, the shading effects can restrain photosynthesis, which influenced nutrient absorption of submerged plants and phytoplankton. After August, the duckweed plays an important part in nutrient absorption while the biomass of submerged plants decreases. The results of the three scenarios have an intersection point in August (see in Fig. 6.). Therefore, we should harvest all duckweed before August and introduce duckweed into wetland after August to achieve better effect of ecological restoration.

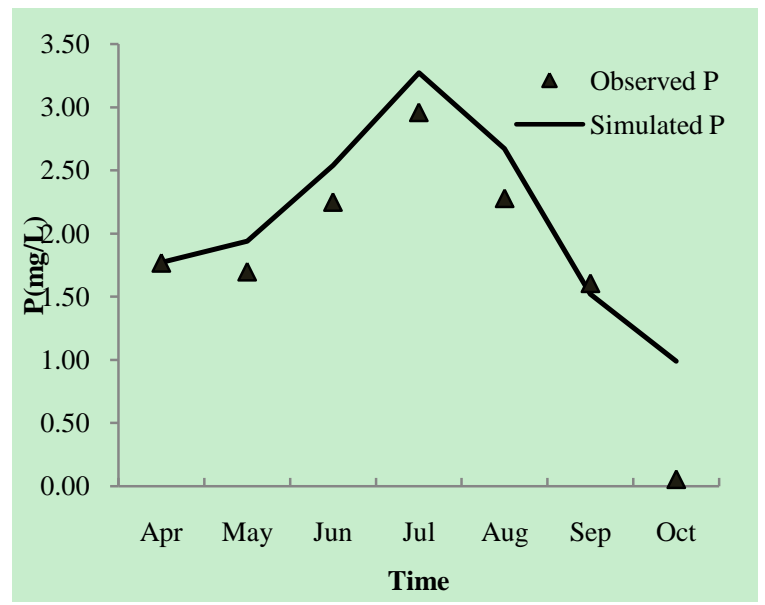

Fig. 5. Comparison of simulations and observations for $\mathrm{P}(\# 2)$.

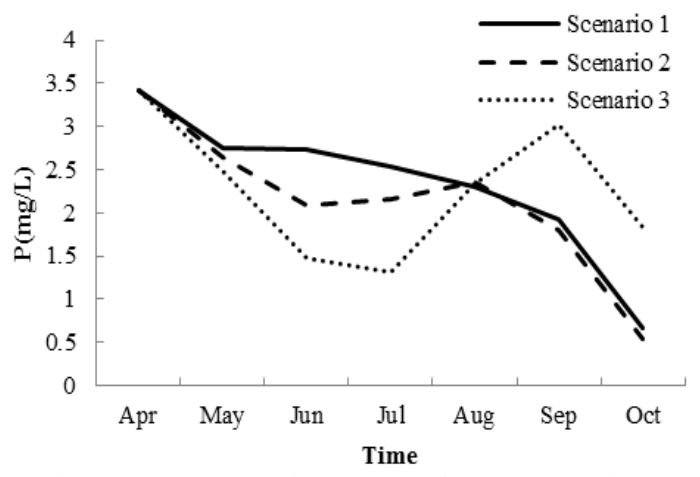

Fig. 6. Comparision of simulations for three scenarios.

\section{ACKNOWLEDGMENT}

Special thanks to the Scientific and Technological Supporting Program of China (2012BAC13B02) and the Natural Science Foundation of China (No. 51279009) for financial support.

\section{REFERENCES}

[1] Mackintosh and Davis, The Importance of Urban Wetlands, Chapter $1.1,2014$.

[2] Y. Chen, "Studies on hydrophytes diversity of wetland in Beijing," M.S. thesis, Beijing Forestry University, Beijing, China, 2008.

[3] X. B. Huang, "Investigation of phylankton, zooplankton and evaluation water quality in Hanshiqiao wetland, Beijing," M.S. thesis, Capital Normal University, Beijing, China, 2009.

[4] S. R. Wu et al., "Evaluation of eutrophication for the Hanshqiiao wetland based on water quality and plankton data," Acta Sci. Circumst, vol. 35, pp. 411-417, 2014. 
[5] P. T. Pinto, L. Allende, and I. O'Farrell, "Influence of free-floating plants on the structure of a natural phytoplankton assemblage: An experimental approach," Journal of Plankton Research, vol. 29, pp. 47-56, 2007.

[6] I. O'Farrell, P. T. Pinto, and I. Izaguirre, "Phytoplankton morphological response to the underwater light conditions in a vegetated wetland," Hydrobiologia, vol. 578, pp. 65-77, 2007.

[7] S. E. Jørgensen, "A eutrophication model for a lake," Ecological Modeling, vol. 2, pp. 147-165, 1976.

[8] F. L. Xu, S. E. Jørgensen, and S. Tao, "Modeling the effects of macrophyte restoration on water quality and ecosystem of Lake Chao," Ecological Modelling, vol. 117, pp. 239-260, 1999.

[9] X.-Z. Kong, S. E. Jørgensen, W. He, N. Qin, and F.-L. Xu, "Predicting the restoration effects by a structural dynamic approach in Lake Chaohu, China," Ecological Modelling, vol. 266, pp. 73-85, 2013.

[10] F. Xu, Z. F. Yang, B. Chen et al., "Development of a structurally dynamic model for ecosystem health prognosis of Baiyangdian Lake, China," Ecological Modelling, vol. 29, pp. 398-410, 2013.

[11] Y. W. Zhao, M. J. Xu et al., "Development of a zoning-based environmental-ecological-couples model for lakes: A case study of Baiyangdian Lake in North China," Hydrol. Earth System Sci, vol. 11, pp. 1693-1740, 2014.

[12] M. Frédéric, L. Samir, M. Louise et al., "Comprehensive modeling of mat density effect on duckweed ( Lemna minor) growth under controlled eutrophication," Water Research, vol. 40, pp. 2901-2910, 2006.

[13] S. Lasfar et al., "Intrinsic growth rate: A new approach to evaluate the effects of temperature, photoperiod and phosphorus-nitrogen concentrations on duckweed growth under controlled eutrophication," Water Research, vol. 41, pp. 2333-2340, 2007.

[14] K. Zhanget al., "The logistic growth of duckweed (Lemna minor) and kinetics of ammonium uptake," Environmental Technology, vol. 35, pp $562-567,2014$

[15] X. C. Jin, S. K. Liu, and Z. S. Zhang, Lakes in China - Research of Their Environment, China Ocean Press, Beijing, China, 1995, pp. 50-51.

[16] J. H. Janse, "A model of ditch vegetation in relation to eutrophication," Water Science and Technology, vol. 37, pp. 139-149, 1998.

[17] T. Lenhartet al., "Comparison of two different approaches of sensitivity analysis," Physics and Chemistry of the Earth, vol. 27, pp. 645-654, 2002
[18] J. E. Nash and J. V. Sutcliffe, "River flow forecasting through conceptual models: part I-A discussion of principles," Journal of Hydrology, vol. 10, pp. 282-289, 1970

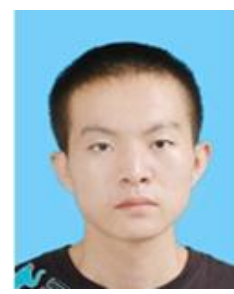

Zhiming Li was born in Tianjin, China on May 22, 1990. He obtained a bachelor degree of environment science from Chinese University Petroleum, Beijing in 2013. Now, he is a master student at Beijing Normal University. His research interests are wetland ecohydrology and eutrophication control of wetland.

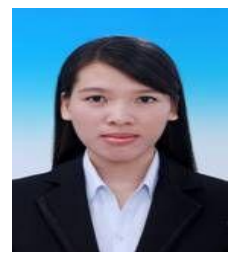

Yanxia Liu was born in Henan province in 1989. She obtained a bachelor degree of environment science from Chinese University Petroleum, Beijing in 2012 Now, she is a master student at Beijing Normal University. Her research interests are wetland ecohydrology and wetland ecological simulation.

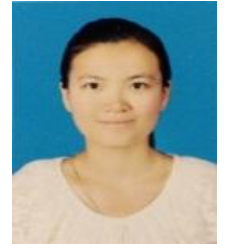

Biqiong Dong was born in Henan province in 1992 She obtained a bachelor degree of environment science from Chinese University Petroleum, Beijing in 2014 Now, she is a master student at Beijing Normal University. Her research interests are wetland ecohydrology.

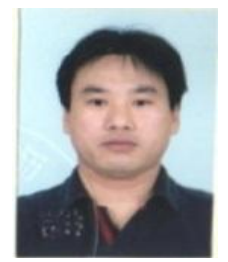

Yanwei Zhao was born in Henan province in 1974. He obtained a bachelor and a master degree of environment science from Northeast Normal University in 1998. He earned his doctor degree of environment science in Beijing Normal University in 2005. His research interests are ecological health and restoration of river basin and environmental assessment, planning and management. Now, he is an associate professor of State Key Laboratory of Water Environment Simulation, School of Environment, Beijing Normal University. 